\title{
Patterns of Use of Computer Support for Environmental Accreditation in Rural New Zealand
}

\author{
Dr Samuel Mann and Ian Brown \\ Otago Polytechnic, Forth St, Dunedin, New Zealand, smann@tekotago.ac.nz \\ Otago Regional Council, Stafford St, Dunedin, New Zealand, ianb@orc.govt.nz
}

Key words: Rural, Database, Policy, Impact, Assessment, Verification, IS014000, Farm plan.

Abstract: $\quad$ Formal environmental auditing practices have largely been the domain of large organisations. This paper describes the results from the use of a computerbased process for accreditation at the farm level. This study of the pattern of use of such a system enables both the fine-tuning and continued deployment of this system, and the appropriate design of similar schemes. The use of the system increased the quality of a set of accreditation documents while reducing the development time from six months to less than two hours.

\section{INTRODUCTION}

This paper describes the evaluation of the use of a decision support system: Ag-vantange. This is a computer-based system that was designed to facilitate the production of farm management plans suitable for accreditation according to environmental, product quality and safety schemes. The issues involved in developing such an accreditation scheme and the design of the computerised system have been discussed previously (Mann and Brown 1999), and are briefly covered for background below. The main subject of this paper is the evaluation of the use of the system. A study of the pattern of use of such a system will enable both the fine-tuning and continued deployment of this system, and the appropriate design of similar schemes.

\section{DISTRIBUTED RURAL ACCREDITATION}

One of the most effective ways of verifying that there is substance to any claim of appropriate quality is to be involved in an "assured production"

The original version of this chapter was revised: The copyright line was incorrect. This has been corrected. The Erratum to this chapter is available at DOI: 10.1007/978-0-387-35503-0_29 
programme whereby claims of sound management can be verified by independent audit. Such structures, however, have largely been the domain of large organisations; major manufacturers, service providers, hospitals and the like. Such organisations can support the overhead required to develop policies and practices to meet the requirements of accreditation and audit. Accreditation schemes may apply at various levels including ISO, particularly 9000 and 14000 , industry standards, product labelling schemes and local, regional and national legislation. It is becoming increasingly apparent that primary producers too will need to provide evidence of the appropriateness of production systems used to grow their products. In primary production, this 'appropriate' means production that is sound in terms of environmental concerns, animal health and safety, and product quality. For different products, different standards apply and there is a myriad of potential standards (eg Eco-management and auditing scheme, Integrated Fruit Production Programme, Project 98, Biogrow, Fernmark etc. see NOSLAM 1998).

There are three major difficulties in applying these accreditation schemes to primary production. The first is that the industry is distributed. While the industry as a whole is of significant size, the individual producers are small family holdings, usually with one or two employees. Such producers cannot support the overhead needed to individually comply with accreditation. Second, primary production is a very diverse industry. On a single property there may be as many as fifty distinct activities carried out. This results in a very complex set of procedures in order to ensure that all activities are considered. The third difficulty is one of information. In order to comply with the legislative requirements of different levels of government, as well as industry standards, the policy and regulatory documents for each organisation must be found, read and assimilated. When combined with the large number of activities that may occur on a farm, the danger of losing sight of the objective under a pile of paper becomes more than a potential.

Mann and Brown (1999) described a model for group environmental accreditation. The scheme was designed to pursue accreditation through ISO14001 as it was believed that the strict standards provided would be applicable to other schemes and would be compatible with legislation (including New Zealand's Resource Management Act). Assurance systems including environmental, animal welfare, and food safety could be run under the same process. The scheme relied on each individual farm receiving accreditation from the group, the advantage is that much of the bureaucratic work can be performed at a group level, and, most importantly, by the computer. The work described by Mann and Brown (1999) was performed in conjunction with a rural community group: the North Otago Sustainable Land Management Group - NOSLaM. The goal of this group was 'to 
facilitate the operation of an integrated management system by producers that allows product claims to be verified' (Ludemann et al. 1996, NOSLaM 1995, NOSLaM 1998).

The process carried out by each farmer was essentially a filtering system that enabled him or her to select the management actions that were required to enable accreditation. These management actions were contained in a Hazard Analysis Management Response Table (HART: functionally equivalent to a ISO 14001 Environmental Impact/Risk Analysis Table). In order to gain accreditation the farmer had to demonstrate the decisions that led to the generation of the HART. This required a formal significance analysis stage. The flow for the entire exercise is represented in Figure 1 where the goal was the production of the Ag-vantage document. This document consisted of approximately 30 pages, unique for each farm.

Ag-vantage was originally developed as a paper-based system and the process was carried out on 15 farms in North Otago. The document production was labour intensive for both farmers and consultants, there being much duplication of effort. Consistency was hard to maintain, both internal (within documents) and external (between documents). The process also required a transcription role once a longhand version of the document had been obtained. After six months, of the 15 farm plans initiated, only six resulted in a complete document and even with these, major inconsistencies remained.

\section{DECISION SUPPORT}

The manual process of completing the Ag-vantage documents did not meet the aim of providing a mechanism for distributed and complex accreditation. A computer system was developed that had the goal of producing the bulk of the Ag-vantage document within a single sitting, and that farmers could walk away with a complete draft document (Mann and Brown 1999, for example see Tisdale 1999).

Hay (1998) described how the role of a data model is to describe the essence of the enterprise. In these terms the essence of the Ag-vantage was to provide evidence of appropriate management and of appropriate decision making in this management. The essence of the computerised Ag-vantage in turn, was the use of as much pre-generated material as possible and simple procedures for decision-making. The farmer only has to tick off which activities they perform and the list of potential impacts is presented, according to the organisations they wish to be accredited to. Each potential impact is then scored for significance (Figure 2) and the draft Ag-vantage document is generated. Beyond this basic structure there are many options, the levels of significance may be altered, paddocks and "land management 
units" (LMUs) may be considered. The LMUs are areas of land which react in a similar manner to different management activities. The assessment is completed for each LMU (or combination) where management/effects are likely to differ.

The system may also be described with reference to the entityrelationship-diagram (Figure 3). The negative impacts associated with each policy held by an organisation may be considered to be caused by different activities. For each activity/impact combination the group writes a row in the HART chart. Each cell in the table is stored as a separate block of text. The row in the table is included in an Ag-vantage document if it is assessed as significant or if it is a 'regulatory alert'. 'Regulatory alert' means that if an activity is carried out, it should be included in the Ag-vantage documents (eg management of hazardous waste). Each paddock on the farm may assigned to a number of land management units. These LMUs describe areas of the farm that are either managed differently or behave differently under the same management. When initiating an Ag-vantage document the farmer selects the activities they perform and the organisations whose policies they wish to adopt. From these selections a list of potential negative impacts is automatically generated. The farmer steps through those impacts to assess the impacts. This involves a series of questions to assess the likelihood of that impact occurring and the consequences of such an event occurring. The likelihood questions concern the past occurrence of the impact, the vulnerability of the site to the impact, whether monitoring is carried out and whether preventative measures are taken to avoid the impact. The consequence question combines severity, extent and reversibility. The answers to these questions are compared to a significance threshold grid that is set by the group but may be altered by the individual farmer. For significant impacts the HART chart is presented. Within each cell text may be omitted or altered. New points may be added for individual farms that may be later adopted by the group. In addition to the HART chart, management reports may be produced. These are designed to encourage the integration of the management plans into actual farm management (eg paddock-based goals and monitoring plans) and facilitate audit procedures (Figure 4). 


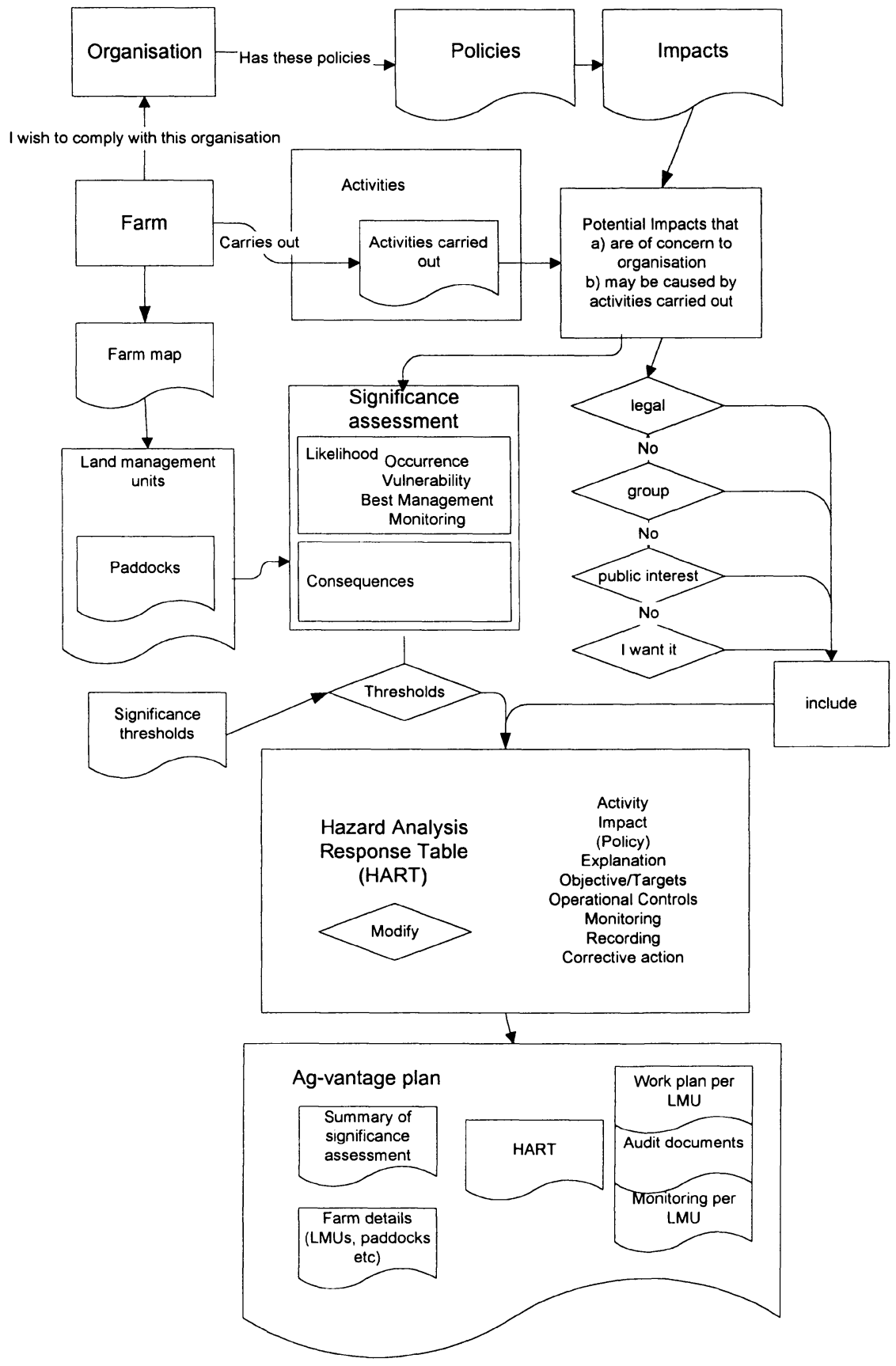

Figure 1. Ag-vantage process (only the assessment and documentation stages shown). 


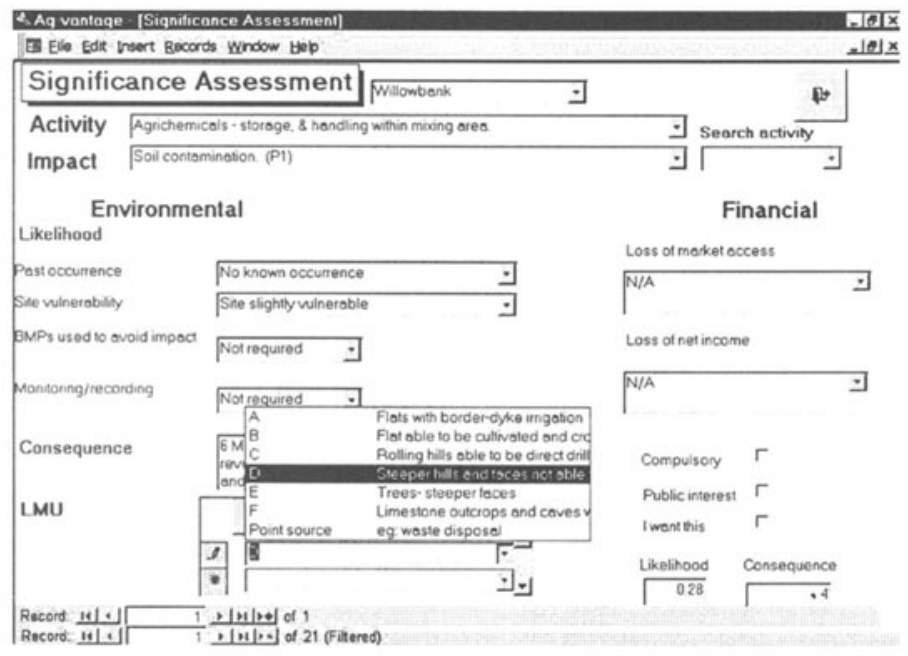

Figure 2. The significance assessment is the focus of the whole system. Assessments are carried out where there are impacts of concern to the accrediting organisation that are potentially caused by activities of that farm. The scores are used to determine whether the activity/impact should appear on the HART chart.

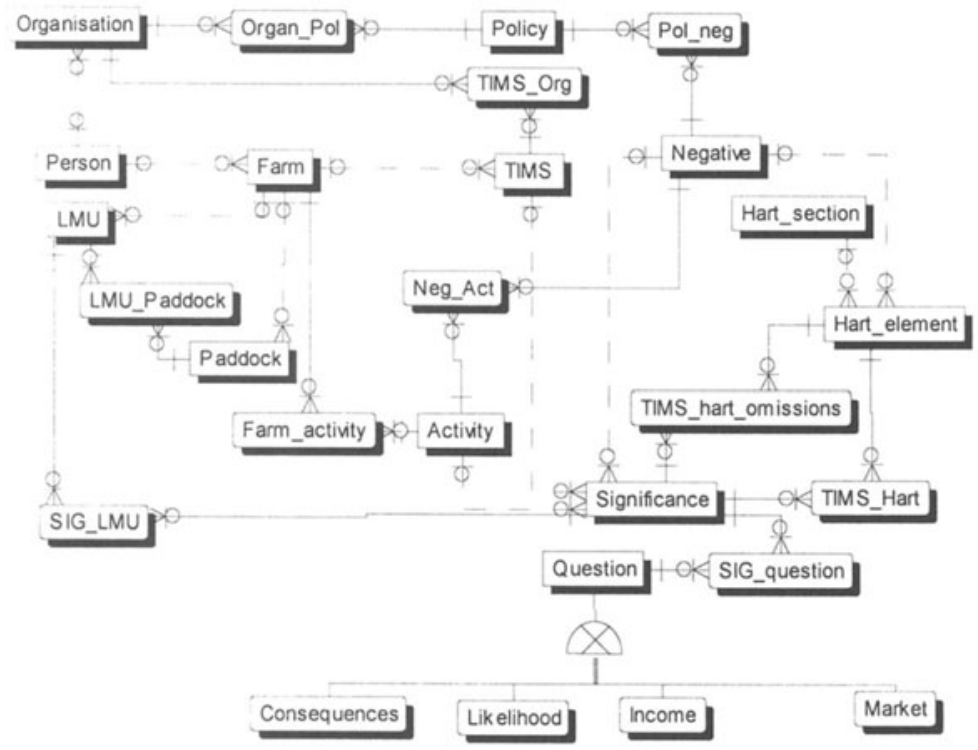

Figure 3. Entity-relation diagram for Ag-vantage (following IE methodology) 


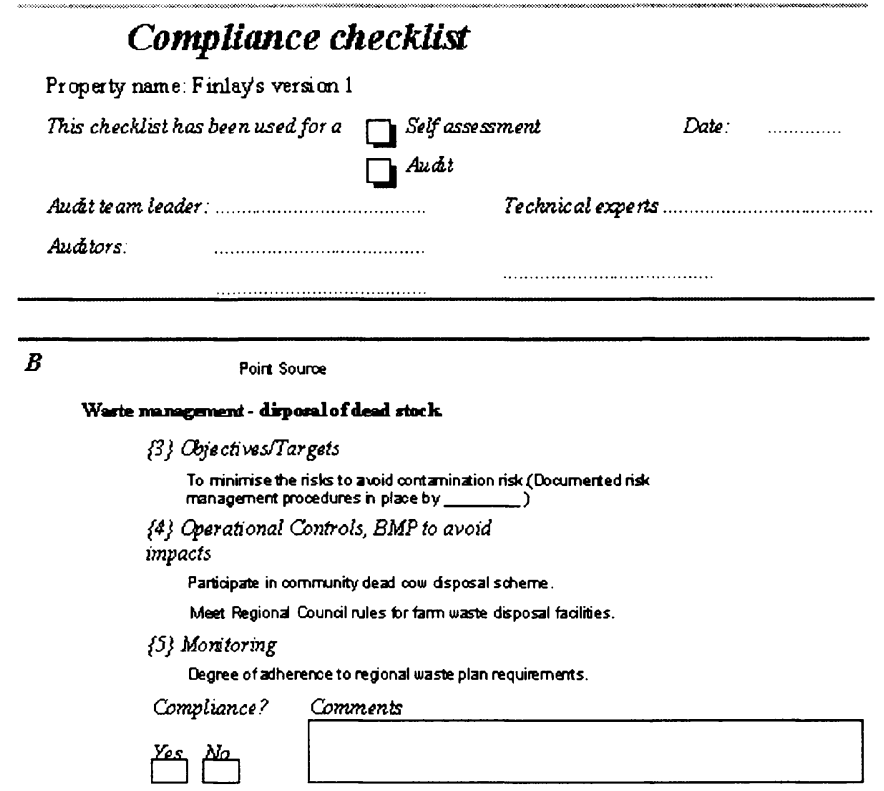

Figure 4. Section of a report. Preformatted information is combined with specific HART information for that property. The example shown is for the auditor's checklist

Table 1. Environmental Risk Report for sample property. 'Considered' is the number of Activity/Impacts for each resource area, these may be sufficiently significant to warrant an entry on the HART chart according to the likelihood and consequence scores.

\begin{tabular}{lllll}
\hline Resource Category & Activity/impact & HART & Likelihood & Consequence \\
\hline Soil Resources & 13 & 2 & 0.92 & 1.00 \\
Market Expectation & 5 & 1 & 1.39 & 1.60 \\
Human Health Risk & 3 & 0 & 0.83 & 1.00 \\
$\begin{array}{l}\text { Quality of water } \\
\text { resources }\end{array}$ & 13 & 0 & 1.05 & 0.54 \\
Quantity of water & 5 & & & \\
resources & & 1 & 0.00 & 0.00 \\
Vegetation and fauna & 1 & 0 & & \\
Pests & 5 & 5 & 1.15 & 0.80 \\
Air quality & 3 & 0 & 2.41 & 2.11 \\
Wider community & 2 & 0 & 0.83 & 1.00 \\
\end{tabular}

Beyond the outputs intended for farmers, the Ag-vantage process generates much information of interest to environmental managers. Table 1 shows summary information for a sample farm. It can be seen that of 54 activities, 9 had sufficiently significant impacts as to warrant an entry on the HART chart. Further, it can be seen that although both Soil resources and Water quality policies are affected by 13 activities, only the former had any 
significant impacts. Fewer activities affected Pest polices but more than half of these warranted HART entries. Such information is considered very valuable by environmental managers and allows validation of the process with other sources of information (soil data, pest count data etc.).

\section{PATTERNS OF USE}

Ag-vantage has been adopted by eight organisations including government agencies and community groups. It is of concern to these organisations that the model can be shown to produce worthwhile results. The remainder of this paper examines the results from 81 farms $^{2,3}$ with a view to determine the range and patterns of responses. It is intended that this analysis will enable improved performance of the current system as well as facilitate the appropriate design of future systems for environmental accreditation.

\section{RESULTS}

The ORC and NOSLaM organisations have developed twelve policies for use in Ag-vantage. These they have associated with three 'dummy' organisations: Environmental, Food and Product Safety, and Animal Health and Welfare. These policies are linked to 102 potential negative impacts. These negative impacts in turn are associated with 92 activities. Together the impacts and activities form 124 combinations that expand out to 1081 cells on the HART table. When printed out, the entire HART chart forms a 127 page document and represents a considerable investment in time and resources by the two organisations.

Farmers were presented with activity/impact combinations for assessment according to the organisations under which they were seeking accreditation and activities they carried out. With the exception of one farm where every activity was selected, most farms were in the range of 10-35 activities (av: 23.58, sd: 12.68). When combined with the impacts, most farmers considered between 15 and 40 activity/impact combinations (av: 32.92, sd: 13.60). Most activities (67) were related to just one impact, and 15 to two (av: 1.34 , sd: 0.72 ). Although only six activities had more than two associated impacts, as Figure 6 shows, the impact of this is still

${ }^{2}$ The generic 'farm' and 'farmer' are used as shorthand for the wide range of properties in the sample that included orchards, market gardens and the like, through to largescale dryland and mountain sheep-stations.

${ }^{3}$ These are the properties for which the Ag-vantage process was carried out under the auspices of the Otago Regional Council and NOSLaM. To date approximately 200 other farms have been through the Ag-vantage process. 
significant. The significance assessment is also repeated for any LMUs where effects are expected to differ. Although all farmers used the LMUs (Table 2) the repeat assessment feature was not used a great deal and only increased the assessment by $31.15 \%$. All but one of both the activities and impacts were used in significance assessment. The paddock based analysis feature was unused.

Table 2. Count of LMUs per farm ("point-source" is added by default)

\begin{tabular}{ll}
\hline LMU count & Percent of farms \\
\hline 2 & 8.70 \\
3 & 7.25 \\
4 & 27.54 \\
5 & 13.04 \\
6 & 18.84 \\
7 & 17.39 \\
8 & 7.25 \\
\hline
\end{tabular}

When the significance assessment completed by the farmers was fed forward to generate the HART chart, all but two had less than 20 rows on the HART chart, the majority had between five and 15 rows. This is complicated by the ability given to farmers to modify the significance threshold. Half the sample raised the significance threshold in order to restrict the number of rows on the HART chart.

All of the activity/impact combinations that were assessed made it onto the HART chart at least once. While the those activity/impacts that were assessed more frequently also appeared on the HART chart more frequently (correlation coefficient 0.6617 ), being assessed more frequently did not increase the likelihood of appearing on the HART chart (correlation coefficient 0.2828 ).

The majority of HART items appeared as a result of the Environmental Significance $(82.43 \%)$. Fewer (though with some overlap) were because of 'Regulatory Alerts' $(27.40 \%)$ or 'I want this' (13.27\%). The Financial Significance was almost entirely unused. Other than artefacts of the equation used to determine the "Environmental Likelihood", no relationships could be detected in the responses to the Significance questions (Table 3). Each HART row was used an average of 6.88 times. The distribution ranged up to 54 although the distribution was uneven with 90 being less than 20 .

Time records were kept during one workshop. This smaller sample showed that the significance assessment process took less than 80 minutes but was not related to the number of impacts considered. 


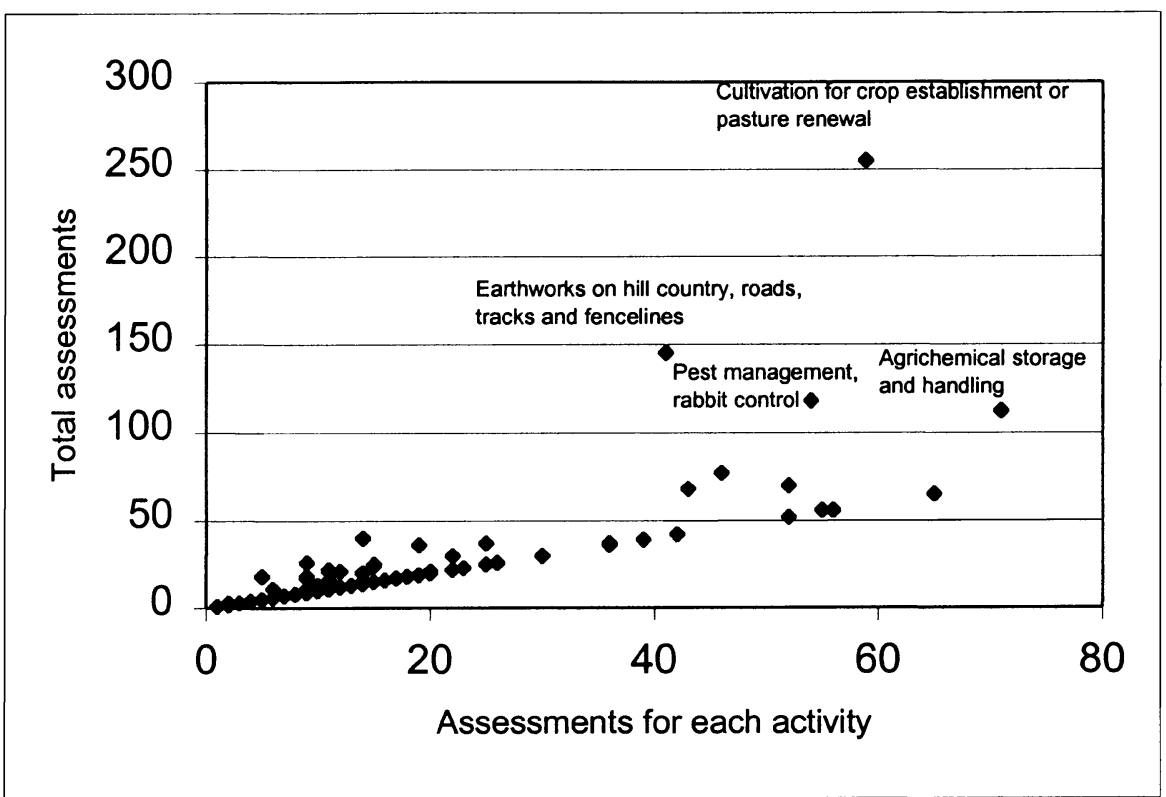

Figure 5. Relationship between number of assessments (by activity) and repeat assessments.

Table 3. Correlation matrix of responses to Significance Assessment questions.

\begin{tabular}{|c|c|c|c|c|c|c|}
\hline & 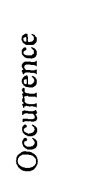 & 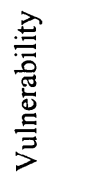 & 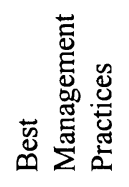 & $\begin{array}{l}\stackrel{0}{E} \\
\stackrel{0}{0} \\
\stackrel{0}{\Xi} \\
\stackrel{0}{\Sigma}\end{array}$ & 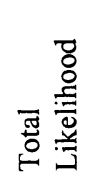 & 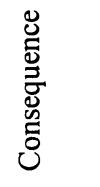 \\
\hline Occurrence & 1.0000 & 0.4271 & 0.1938 & 0.2450 & 0.7300 & 0.4867 \\
\hline Vulnerability & & 1.0000 & 0.4382 & 0.4909 & 0.8100 & 0.5137 \\
\hline BMPs & & & 1.0000 & 0.6328 & 0.6556 & 0.3359 \\
\hline Monitoring & & & & 1.0000 & 0.7389 & 0.3383 \\
\hline Likelihood & & & & & 1.0000 & 0.5875 \\
\hline Consequence & & & & & & 1.0000 \\
\hline
\end{tabular}

\section{DISCUSSION}

The Ag-vantage system illustrates a computer-based system for distributed environmental accreditation. The Ag-vantage process has enabled the delivery of a complex suite of accreditation materials to an industry that is distributed and diverse. The results described above are derived from the actual use of a computer system designed to generate management documents and sufficient evidence of process to allow accreditation. 
The computer-based Ag-vantage system is very much faster than the paper-version ( 80 minutes instead of several months). The significance assessment is mentally hard work, so to maintain farmer energy levels it is important that the time spent during the significance assessment be kept to a minimum. This is also a bottleneck in farmer workshops. Unfortunately this analysis has not determined any areas where the process could be streamlined. The questions asked in significance assessment were poorly correlated with each other but all well correlated with the final values. This suggests that all the questions contribute and should be maintained. The repetition with LMUs was not used a great deal which suggests that farmers used this frugally, only using it when a different LMU would be dramatically different in effect. Similarly well used was the ability to vary significance thresholds to restrict rows in the HART chart and consequently the management actions required for accreditation. This shows that despite the rigidity imposed by the accreditation system, there is still sufficient flexibility for sensible decision making.

The benefits of the Ag-vantage approach were achieved by examining the processes, distinguishing which information could be pre-generated and simplifying the decision-making procedures. The pre-generated entire HART chart is a substantial document and each component represents an investment by the organisations. It is encouraging that almost all of the HART rows where used in farmers' Ag-vantage documents. There was no consistent relationship that could be used to predict the worth of individual HART rows.

Environmental managers are able to take use summary information for each farm, as a 'health check'. This can also be informative at a meta-level. The policy relating to 'Waste management' was assessed 82 times but only considered significant 14 times. 'Quantity of water resources' however, was assessed 24 times but was considered significant nearly half of these times, suggesting that it is an issue which is taken seriously where it occurs. The use of dummy organisations as a substitute for policy categories is of concern.

It is the farmers themselves performed the significance assessment. The goal was to reduce the potential impacts to those that require immediate attention. There is a danger that issues such as those covered by the 'Natural features' policy may never quite make it to the HART chart. Another area of concern is the use of farmer-defined LMUs rather than the more objectively defined Land Resource Inventory units (Barringer et al. 1998). This paper has not considered the environmental efficacy of the Ag-vantage approach. This will be the subject of a future paper.

We believe that a review of this type is a worthwhile process for developers and users of information systems. It is hoped that developers of 
other distributed environmental accreditation systems will benefit from this discussion.

\section{ACKNOWLEDGMENTS}

The authors wish to acknowledge the support of David Hewson and David Horn and the NOSLaM group. The feedback of workshop participants was vital, particularly those brave enough to test the early waters. We would also like thank the Otago Regional Council and the Otago Polytechnic for their continued support of this project.

\section{REFERENCES}

Barringer, J., Wilde, H., Willoughby, J., Burgham, S., Hewitt, A., Gibb, R., Newsome, P., \& Riijkse, W. (1998). "Restructuring the New Zealand Land Resource Inventory to meet the Changing Needs for Spatial Information in Environmental Research and Management". In Firns P. (ed) Colloquium of the Spatial Information Research Centre, Otago University (10):25-33

Hay, D. C. (1998). “Making data models readable.” Information Systems Management 15(1): 21-33.

Ludemann, G., Hewson, D. and Green, R. (1996). North Otago Sustainable Land Management Group: Assisting the North Otago Community to Move Towards the Goal of Sustainable Land Use. New Zealand Grasslands Conference, Oamaru. 8p

Mann, S. and Brown, I. (1999), "Decision Support for Environmental Accreditation" New Zealand Journal of Applied Computing and Information Technology 2(2):39-53

NOSLaM. (1995). North Otago Sustainable Land Management Guidelines. Hewson, D. J. and Mann, S., (Eds) Dunedin, NZ, North Otago Sustainable Land Management Group and Otago Regional Council

NOSLaM. (1998). Farming for the Future, Sustainable Farming Through Total Integrated Management Dunedin, NZ, North Otago Sustainable Land Management Group and Otago Regional Council.

Tisdale, G. And D. (1999) Ag-vantage Environmental farm plan, Stoneblend. http://www.noslam.co.nz/agvantage/tisdall.pdf

A demonstration version of the Ag-vantage system may be obtained from the following url: http://bit.tekotago.ac.nz/ sam/research/webpage/tims.html 